\title{
Proof of concept of Vehicle to Infrastructure Power Line Communication link for tramway CCTV
}

\author{
Hatem BELHASSEN ${ }^{1,2}$ and Eric VERNEY ${ }^{3}$ \\ ${ }^{1}$ BEAMTEK SAS, 145 Av Gustave Eiffel, Meyzieu, France \\ ${ }^{2}$ ImViA Laboratory, Univ of Burgundy, Franche-Comté, France \\ ${ }^{3}$ Hubert Curien Laboratory, Univ Lyon, UJM-Saint-Etienne, France
}

\begin{abstract}
In the Vehicle-to-Infrastructure (V2I) context, the issue of broadband connected trains presents a number of technical and economic problems. Such broadband links would be benefit for both passengers and security needs. Several technical solutions are available, in particular wireless ones like Wireless Access in Vehicular Environments (WAVE), Long Term Evolution (LTE) or 5G, but we explore here the feasibility of achieving this connectivity, dedicated to trams security application, via Broadband over Power Lines (BPL) technology through tramway power supply cables. In this paper we investigate the possibility of connecting a tramway to its security command post in order to transmit real time video streams through BPL. The Proof of Concept (PoC) is presented through the characterization of the channel, the performances of the physical layer, the measurement of available Round Trip Times (RTTs) and bit rates. Then we demonstrate in real-world a streaming of Closed Circuit TV (CCTV) from two tramway embedded cameras to the security command post. The PoC was carried out on the tramway infrastructure of the city of Lyon. Through this PoC, we have demonstrated the possibility of equipping a complete commercial line with BPL guaranteeing a bit rate of 60 Mega-Bytes per Second $(\mathrm{Mb} / \mathrm{S})$ and presented a deployment projection of the BPL solution for dynamic context (moving tram), based on Power-Line Communication (PLC).
\end{abstract}

Index Terms-Vehicle-to-Infrastructure (V2I), Broadband over Power Lines (BPL), smart city, smart transportation, realtime video streaming, Closed Circuit TV (CCTV), Power-Line Communication (PLC).

\section{INTRODUCTION}

V2I communications mainly concern data exchange between smart vehicles and the infrastructure via wireless networks, in particular through standards such as IEEE 1609 WAVE and IEEE 802.11p, with objectives of safety and traffic efficiency. Different wireless solutions based on LTE have been explored [2], or even Bluetooth in [1]. Several articles are available in literature comparing LTE based solutions to IEEE 802.11p standard [2]-[4].

In the context of urban rail networks, there are a multitude of existing reliable safety networks and standards. They are low rate and use carriers between $39 \mathrm{KHz}$ and $100 \mathrm{KHz}$. These networks have a Safety Integrity Level (SIL) of 2, 3 or 4, and allow the exchange of information between vehicles and the infrastructure.

However, today the urban rail transports are witnessing the emergence of new broadband needs for passengers safety, such as video streaming from on-board cameras to the security command post. Different technical issues are available, for example wireless V2I standards, but this implies the installation of dedicated antennas, which requires a considerable investment [3], generating an additional cost for the transport operators. A cheaper alternative is to transmit through the existing trams power grids thanks to broadband PLC.

The use of the electrical wiring for data transmission exists since the $19^{\text {th }}$ century [5]. In recent decades PLC has drawn the interest of industrial, researchers and standardization organizations [6], and PLC systems experienced an increased deployment. Thanks to the use of Orthogonal FrequencyDivision Multiplexing (OFDM), which allows the transmission of information on noisy and frequency selective channels as shown in [7], it became possible to use heterogeneous types of power lines as transmission lines for PLC signals. From 2010, PLC devices became ubiquitous whether for in-door use [9] (Home Plug) or out-door (Smart Grid) [8], [10]. Thanks to the broadband over power lines method, PLC modems allow bit rates about $200 \mathrm{Mb} / \mathrm{S}$ in industrial environment (IEEE Std 1901-2010), and about 1.2 Giga bytes per second for indoor applications with IEEE Std G.hn. However, the use of PLC networks is not limited to these cases, it is also used in the field of smart transportation (trains [11], avionics [12], [13], vehicles [14], [15], ships [16], [17]) and smart grids [18]-[21].

In [22] and [23], authors proceeded to a bottom-up statistical PLC channel modeling applied to indoor transmission lines, in the range 0-30 $\mathrm{MHz}$. In this study, we investigate, in a topdown approach, the use of the broadband PLC technology, in the 4 to $34 \mathrm{MHz}$ frequency range, applied to tramway V2I context since the feasibility of broadband PLC on Low-Voltage Direct Current (LVDC) distribution system was demonstrated in [24]. Unlike the reference [25] which tested a vehicle PLC link, available only when the vehicle is stopped to recharge, our objective is to connect a moving tram to a distant security command post. On-board cameras video stream is transmitted on the tram's power supply network.

The reminder of this article is organized as follow : First, we present general considerations and the pilot site (operating tramway lines in Lyon, France). Second, we characterize the channel through signal to noise ratio and channel capacity, as well as the line impedance and noise properties of its environment. Finally, in last section, we present measured bit rates and round trip times (RTT) on tramway operating lines, routing issues and topology. We conclude this section by presenting implementation, and making a deployment projection of the PLC solution for dynamic context (moving tramway). 


\section{APPLICATION CONTEXT}

\section{A. General considerations}

Every year, more than 15 billion $€$ are lost due to operation interruptions in European public transportations. For example in Lyon, the local transport operator loses $1500 € /$ minute/tramway line every operation interruption. In fact, interruptions are due to many causes, such as accidents, vandalism and abandoned luggage. Many of these incidents could be limited or better handled if public transport operators had real-time Closed Circuit TV (CCTV) streaming. These operators, as well as authorities, aim to improve public transport attractiveness by making them safer.

Despite the presence of on-board cameras in several European trams and metros, it is still challenging to visualize the real-time video streams of CCTV from security command post.

In such a context, it is possible to use wireless solutions such as LTE, 5G, or WAVE, but they are costly in underground lines and hostile environment since antenna redundancy is necessary to guarantee a high quality of service.

Due to their high deployment costs (for example $10 \mathrm{M€}$ for $12 \mathrm{~km}$ in the city of Toulouse [26]), few European cities have opted for these wireless solutions. In fact, those systems pose a number of issues, such as deployment and subscription costs or security of transferred data.

Proposing PLC solution, for dynamic context (moving tramway), as a robust, low cost and complementary technology in the global smart transportation market, which is expected to reach $149 \mathrm{~B} \$$ by 2022 [27], is an important challenge.

\section{B. Motivation and presentation of the pilot site}

The objective of this study, carried out from the end of 2016 until 2018 in France on the public transport network in Lyon, is to define the feasibility of the large-scale deployment of a technical solution based on the PLC system, enabling the transmission of video streams from moving tramway on-board cameras to the security command post, using the overhead contact lines. The PLC network presented in this paper is effected with modems marketed by the company BEAMTEK. The technical presentation of the used modems is given in section III and IV. Currently, Lyon's tramway network has 5 lines with a total length of $80 \mathrm{~km}$. Each line consists of several sections, fed by independent substations every $1.3 \mathrm{~km}$ or so. We realized our PoC on $3 \mathrm{~km}$ of the $15 \mathrm{~km}$ of the T2 line which is well representative of the tramway environment in this city since it passes under a railway station, on a river bridge, goes along and spans the railway and is crossed by several tramway lines.

Indeed, the tramway network of several kilometers can be considered as a redundancy of $3 \mathrm{~km}$ portions. In each portion, tramways exchange data with the overhead contact line using PLC technology. These portions can be connected to the security command post via an existing optical fiber backbone that runs along the tram tracks. This fiber is currently used for ticketing and dockside cameras, and is sufficiently sized to accommodate additional links; it is accessible in the technical areas below the docks.
Our $3 \mathrm{~km}$ experimental line is electrically fed by 3 different substations, which implies, at least, the same number of breaks in overhead contact lines. To maintain the continuity of the IP network, it was necessary to double the PLC system (capacitive couplers and modems) around each break point. The PLC installation used to make the tram infrastructure smart is composed of a static PLC system and an on-board PLC system. The static system, composed of modems spaced an average of 350 meters, allows PLC network creation on the overhead contact line (750V DC). Each PLC static access point is composed of PLC modem and one or two capacitive couplers [28] (BEAM-Ccu-HTA-Undercap Capacitive Coupler $25 \mathrm{kV})$. The coupler is designed and certified for HTA use up to $25 \mathrm{kVAC}$. The coupler is connected on one side to the overhead contact line and on the other side to the rail, thus the line constitutes a transmission line excited by the PLC signal, which input impedance will be presented in next section. In addition, to establish a communication from the tramway to the overhead PLC network, we install 2 PLC modems on-board and connect them to a platform to manage the handover since the modems are natively static-routed. We use the same model of couplers to inject PLC signal in the overhead contact line through the pantograph. Couplers are placed on the tramway roof and are connected to PLC system placed on traveler zone via shielded cables. Some information related to deployment and implementation are hidden or not specified for confidentiality reasons.

\section{EXPERIMENT AND CHARACTERIZATION}

In this section, we first present in subsection A "channel characterization": surrounding noises characterization and line impedance measurement. Then, in subsection B, "physical layer performances", we present the SISO channel set up by the modems and measure the channel capacity.

The results presented come from 3 measurement campaigns. A portion of the installation is illustrated in figure 1 below:

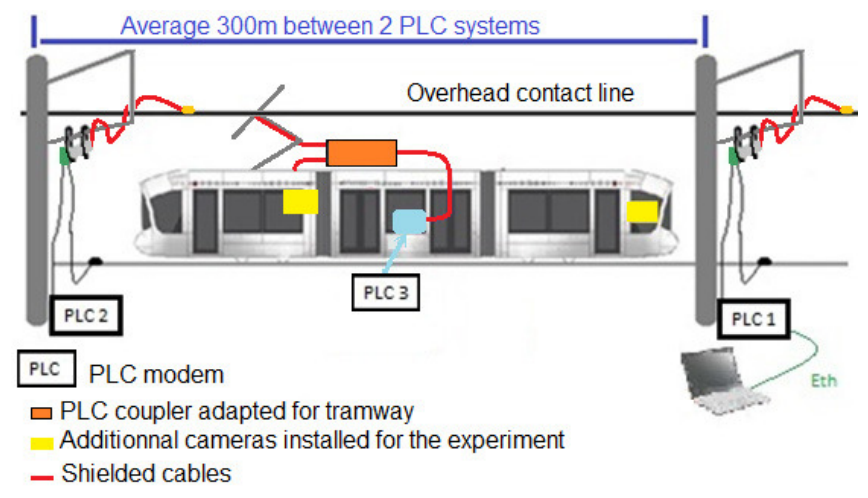

Fig. 1. Experimental installation of the tramway PLC link.

The first measurement campaign was conducted at the tram maintenance center to characterize the overhead contact line. The second measurement campaign was done in town during commercial exploitation and was dedicated to the EMC characterization of the tramway infrastructure and its environment (the city). The last measurement campaign was done by night, 
off commercial exploitation, on a $3 \mathrm{~km}$ section, with 2 trams circulating including one equipped with PLC. On this portion, the entire overhead contact line was covered by PLC network as we equipped 10 feeding points along the line with PLC modems.

\section{A. Channel characterization}

As noise is one of the major drawbacks in PLC, it was necessary to characterize the radio environment of both tramway and overhead contact lines to anticipate possible electromagnetic compatibility (EMC) problems. The PLC signal can be polluted by tramway emissions produced by traction chain, as well as it could disturb the tramway equipment like radio communications for safety and controls. The railway signaling (switching system) can also be polluted by the PLC signal. As the line carries high frequency signals, it has to be considered as a transmission line. Thus, we analyzed the overhead contact line spectral properties (impedance, bandwidth, losses and Signal to Noise Ratio (SNR)) to prove that the PLC signal can be injected and transported over long distances. In the following paragraphs, we show noise measured both in free space inside the tram with a spectrum analyzer, and on the line with the embedded chipset of the modems.

1) EMC consideration: Concerning the tramway safety, there is in principle no interference between the PLC signal and the railway signaling equipment used on the Lyon's tramway infrastructure. Indeed, the used PLC modems, emit between 4 and $34 \mathrm{MHz}$ while the highest frequency carrier used for the tramway signalization is at $100 \mathrm{KHz}$ and the majority of the signaling signals are in the $39 \mathrm{KHz}$ to 50 $\mathrm{KHz}$ band. Therefore, these 2 bands $(39-100 \mathrm{kHz}$ and $4-$ $34 \mathrm{MHz}$ ) do not overlap and we verified that no harmonic of the lower band pollutes the upper band. Thus, no EMC interference should come from the tram safety signals. On the other hand, special care must be taken to ensure that the radiofrequency (RF) emissions of the tramway do not pollute the PLC link. The measurements of these emissions is presented below. To minimize potential EMC problems, the modems and transmission line system (coupler and high voltage cable) are shielded and meet European standards for EMC and highvoltage certification.

The following EMC measurements were performed with a certified Aaronia spectrum analyzer, from a moving tramway on an urban line. The used antenna is an active magnetic tracking antenna (MDF 50400X), covering the band $500 \mathrm{KHz}-$ $400 \mathrm{MHz}$. All measurements were made at a height of 1.20 meter, except those made at the bellows between two cars, at a height of 2.20 meters, to measure the radiations of the power cables connecting the pantograph to the traction chain.

The reference level of electromagnetic (EM) emissions, in the absence of EM pollution sources on the line, was measured during the first campaign close to the tramway rails, with an average level of $-84 \mathrm{~dB}(1 \mathrm{~mW})$. Inside the tramway, this reference measured at the floor level was $-75 \mathrm{~dB}(1 \mathrm{~mW})$.

Once noise references were defined, we measured environmental noises during the second campaign from a running tramway. Measurements taken in the operating cabin show a high noise level compared to the reference (average greater than $-40 \mathrm{~dB}(1 \mathrm{~mW}))$ in the lower band of the spectrum below $24 \mathrm{MHz}$ (framed in cyan in figure 2) with a peak at $13.6 \mathrm{MHz}$ (framed in black) from the RFID validators. The noise level in the cyan frame comes from the electronics of the traction chain (the choppers).

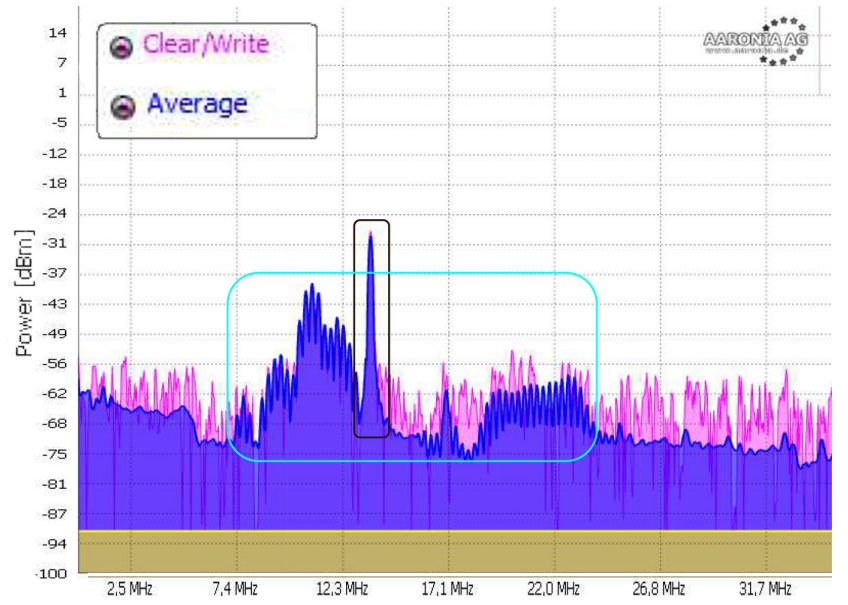

Fig. 2. Screen shot of the EM fields measured inside running tramway.

These emissions measured in the cab are correlated with the disturbances measured in the same frequency range nearby the tram roof supply chain (measured from the inside through the bellows of the tram joint). This area is a critical one for the PLC link since the signal feed cables pass nearby and may be disturbed by RF signals generated by the tram. To overcome these disturbances, we used shielded cables and installed them perpendicular to the power cables to minimize cross-talk. This study of the noisy frequency bands will help to choose the right frequency bands of the PLC modems among 4 to 34 $\mathrm{MHz}$ subcarriers. Its impact on SNR is developed in part B.

2) Line impedance: We measured the input impedance of the line seen from the input of the capacitive coupler on which PLC1 modem is connected, with the Vector Network Analyzer (VNA) [30], to make sure that our signals were well fed into the overhead contact line. The used VNA is Fieldfox N9923A of Keysight Technologies, and the output impedance of the modems is $50 \mathrm{Ohms}$.

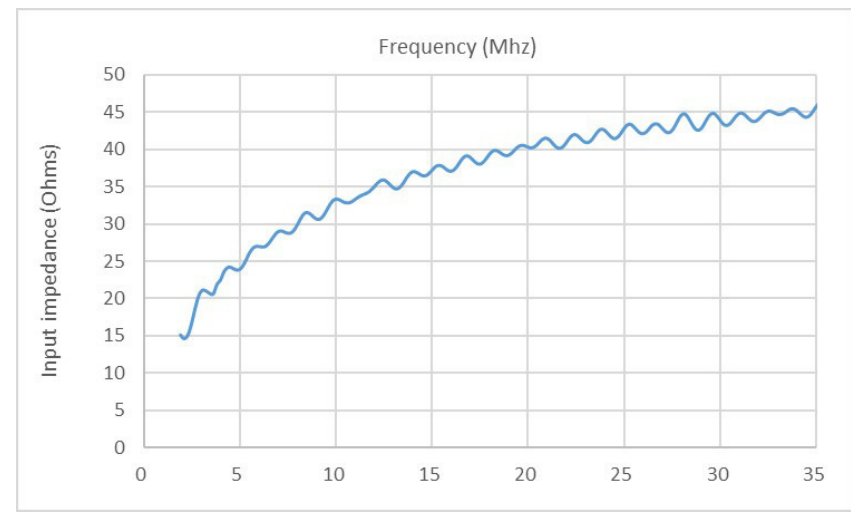

Fig. 3. Input impedance in PLC modem frequency operation band. 
The result of the measurement shown in figure 3 illustrates in the low end of the spectrum a strong mismatch, which leads to an important reflection in this band.

Although the capacitive coupler is sold for use in the 2 to $40 \mathrm{MHz}$ band, with insertion loss less than $2 \mathrm{~dB}$, we have no precise information on its input impedance. Thus, the measured input impedance corresponds to the complete coupling system loaded by the transmission line constituted by the overhead contact line.

In the absence of approved impedance matching systems for railway applications, and in order to avoid significant returns of transmitted signals, we recommend eliminating carriers from the low end of the modem frequency band. To correctly choose the limits of this band, we realized the characterization of the physical layer (channel capacity, SNR) as presented in the next chapter.

\section{B. Physical layer performances}

The used modems are sold with a data rate up to $200 \mathrm{Mb} / \mathrm{S}$ (PHY Layer) on transmission (TX) and reception (RX). They are half-duplex and based on SISO transmission and operating with OFDM modulation [31], [32]. Transmit power is up to $+24 \mathrm{~dB}(1 \mathrm{~mW})$.

Since a full characterization of noise and associated statistics is not achieved yet [6], the real PLC channel capacity is unknown. Instead of trying to identify the different signals present in our samples in the operating line and redo the theoretical calculations, and as the modems are equipped with embedded servers to collect different metrics, we used the modem provided results such as channel capacity for both transmission and reception (TX \& RX), noise level, SNR, number of bits per carrier and display amplification at the reception (AGC RX).

Tests during the first campaign took place at the tram maintenance center, where we equipped the 200 meters of the overhead contact line of the test track with 2 PLC modems to create a PLC network. The train was also equipped with an embedded PLC modem and series of tests and measurements were conducted to define the suitable equipment by testing different materials for connectors, cables, and choosing a narrower frequency band by correlating these results with second campaign observations.

Once the prototype validated at the tram maintenance center, we equipped $3 \mathrm{~km}$ of the operating track of 10 PLC devices, distant from each other by an average of 350 meters.

The first tests were conducted overall the $3 \mathrm{~km}$ portion, with and without moving tramways. The results are as follow.

1) SNR and BPC in the band 4 - 34 MHz: Figure 4 illustrates the Signal to Noise Ratio measured from the embedded PLC modem during the third campaign over the entire available frequency band (4-34 MHz). We observed that the SNR at the bottom of the band and around $22 \mathrm{MHz}$ is too low, this is correlated with the EMC measurements presented in the first section where we see for example the disturbance caused by the RFID tagger at $13.56 \mathrm{MHz}$. To mitigate these disturbances, we use shielded BNC cables which allow to gain $10 \mathrm{~dB}$ of SNR around $22 \mathrm{MHz}$ caused by the tramway traction chain. The degradation of the SNR around this frequency is clearly visible in figure 4 and the improvement is illustrated in figures 6 and 8 .

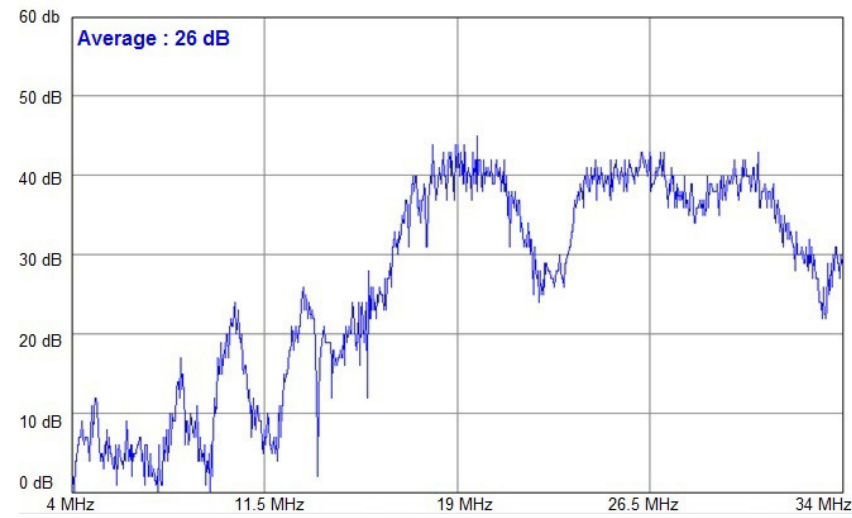

Fig. 4. SNR from the embedded PLC modem, freq band 4-34 MHz.

The SNR illustration and interpretation are correlated with measured bits per carrier (BPC) illustrated below:

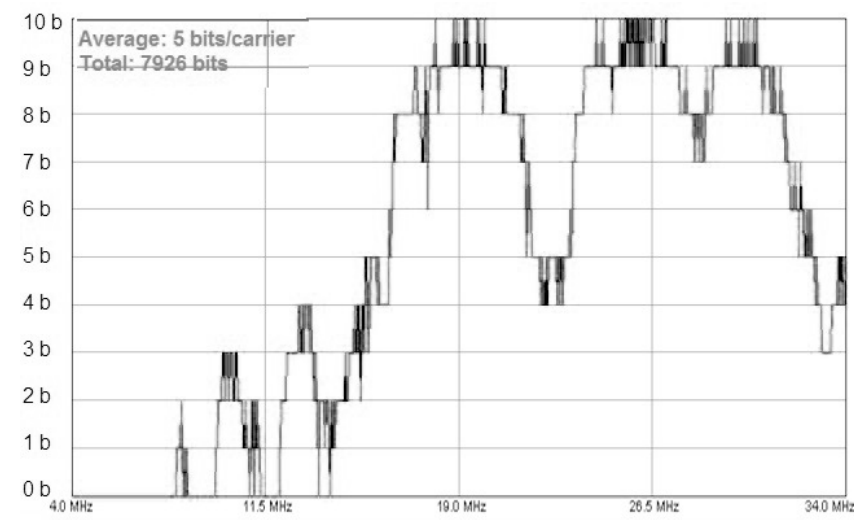

Fig. 5. Bits per carrier from the embedded PLC modem.

The modem offers different sub-frequency bands in the 4 $34 \mathrm{MHz}$ band. These sub-bands can have different widths: 5 $\mathrm{MHz}, 10 \mathrm{MHz}$ or $20 \mathrm{MHz}$. Modems allow PLC installers to overcome surrounding noise by selecting one band or another in the 20 sub-bands offered. The frequency bandwidth affects the channel capacity and therefore the available bit rate, for example for command control applications, 2 or $5 \mathrm{MHz}$ of bandwidth may be sufficient, but for our case, it is not enough. To enable video streaming, we fix bands of 10 or $20 \mathrm{MHz}$.

2) SNR and BPC in the sub frequency band 20 - 30 MHz: We first narrow the frequency band from $20 \mathrm{MHz}$ to $30 \mathrm{MHz}$ and we got a better SNR (from an average of $26 \mathrm{~dB}$ to an average of $35 \mathrm{~dB}$, see figure 6) with minimum AGC $\mathrm{RX}=0$.

However, the limitation of the bandwidth causes a limitation of channel capacity.

Observed bit rates in figure 7 from the embedded modem are 41-43 Mb/S PHY TX and 54-55 Mb/S PHY RX.

3) SNR and BPC in the sub frequency band 13 - 33 MHz: We note that the bit rate could be improved, consequently we try a slightly larger band to maintain a compromise 


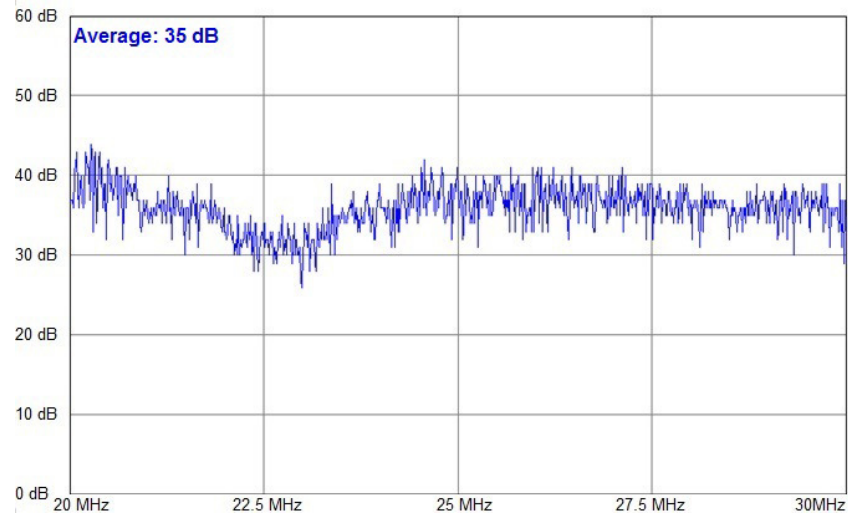

Fig. 6. SNR from the embedded PLC modem, freq. band 20-30MHz.

\begin{tabular}{|c|c|c|c|}
\hline Access & Master & & \\
\hline \multicolumn{4}{|c|}{ MAC: $00: 07: 42.05: B 6.7 F$} \\
\hline \multicolumn{4}{|l|}{ IP: 192.168 .9 .100} \\
\hline \multicolumn{4}{|c|}{ FREQUENCY BAND: 3} \\
\hline \multicolumn{4}{|c|}{$A G C R X$ : Enable $R X G=1$} \\
\hline \multicolumn{4}{|c|}{$A G C T X$ : Enable $T X G=1$} \\
\hline AVAILABLE NODES: & & & \\
\hline [ETHERN ET-AD DR] & {$[\mathrm{PP}-\mathrm{AD} D \mathrm{DR}]$} & PHY TX XPUT & PHY RX XPUT \\
\hline $00: 07: 42.05: B 8: 0 A$ & 192.168.9.102 & $41 \mathrm{Mbps}$ & $54 \mathrm{Mbps}$ \\
\hline $00: 07: 42: 05: B 8: 0 B$ & 192.168 .9 .101 & $43 \mathrm{Mbps}$ & $55 \mathrm{Mbps}$ \\
\hline
\end{tabular}

Fig. 7. PHY TX, RX and AGC RX from the embedded PLC modem.

between the theoretical maximum channel capacity and the physical rate obtained. We choose the $8^{\text {th }}$ band, a predefined modem frequency band, from 13 to $33 \mathrm{MHz}$, thus, we add more than $6 \mathrm{MHz}$ to the exploitable band, and as many subcarriers.

This choice is a compromise between the useful data rate and the bandwidth. In fact, in this band, AGC RX is higher, it is 3 of 7 due to recovered noisy bands (13.56 and $22 \mathrm{MHz}$ ), however we improved the channel capacity.

Obtained SNR is illustrated in figure 8.

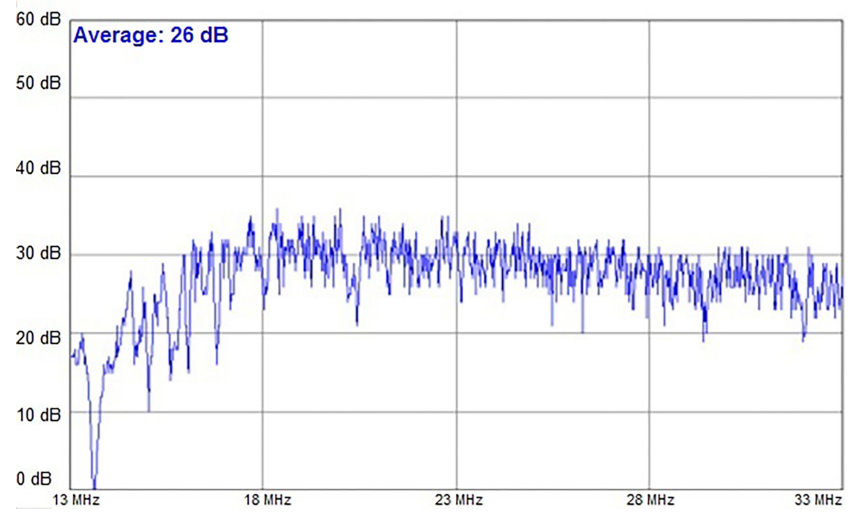

Fig. 8. SNR from the embedded PLC modem, freq. band $13-33 \mathrm{MHz}$.

As mentioned in the introduction, noise remains the major drawback of the PLC technology. Unlike static PLC installations where a model exists [33], and even if electrical modelling exists for tramway infrastructure [34], there is no theoretical transmission line model to statically predict the dynamic behavior of the network (impedance and noise). Thus, to effectively and optimally size a PLC installation, testing PLC modem predefined frequency bands is the only possible method. This approach is valid for both static installations in the context of smart grids and dynamic context: moving tramway (object of this paper).

The main sources of noise come from the choppers of the traction chain. As a result, the approach presented in this article can be reused to implement a PLC network on any tramway installation equipped with the same type of choppers as the tested Alstom trams of the Lyon's public transport network (operating under 750V DC).

EMC audit and selection of appropriate frequency bands should be redone for other types of trains.

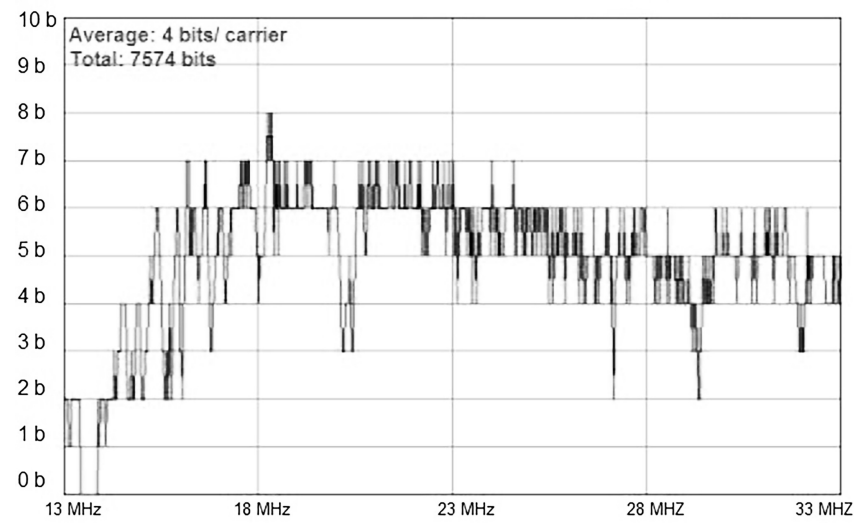

Fig. 9. Bits per carrier from the embedded PLC modem, sub freq. band 13 $-33 \mathrm{MHz}$.

Measurements of channel capacity (see figures 9 and 10) taken over time show an important fluctuation. This can be explained by the dynamic environment (fluctuation of the line impedance due to tramway motion, its operating mode either motor while accelerating or generator while braking).

\begin{tabular}{|c|c|c|c|}
\hline Access & epeater & & \\
\hline \multicolumn{4}{|c|}{ MAC: $00: 07: 42: 05: F 6: 8 E$} \\
\hline \multicolumn{4}{|l|}{ IP: 192.168 .9 .104} \\
\hline \multicolumn{4}{|c|}{ FREQUENCY BAND: 8} \\
\hline \multicolumn{4}{|c|}{$A G C R X$ : Enable $R X G=3$} \\
\hline \multicolumn{4}{|c|}{$A G C T X$ : Enable $T X G=1$} \\
\hline \multicolumn{4}{|l|}{ AVAILABLE NODES: } \\
\hline [ETHERN ET-AD DR] & {$[\mathrm{P}-\mathrm{AD} D \mathrm{DR}]$} & PHY TX XPUT & PHY RX XPUT \\
\hline $00: 07: 42.05: C 1: A B$ & 192.168.9.102 & $89 \mathrm{Mbps}$ & $91 \mathrm{Mbps}$ \\
\hline $00: 07: 42: 05: F 6: B 4$ & 192.168 .9 .106 & $49 \mathrm{Mbps}$ & $57 \mathrm{Mbps}$ \\
\hline
\end{tabular}

Fig. 10. Measurements of TX, RX, AGC RX from the embedded PLC modem, sub freq. band 13 - $33 \mathrm{MHz}$.

In spite of considering a single PLC modems measurement of the physical layer characteristics shown in figure 10, we 
took different samples at equal intervals and represent them in curves below, in figure 11.

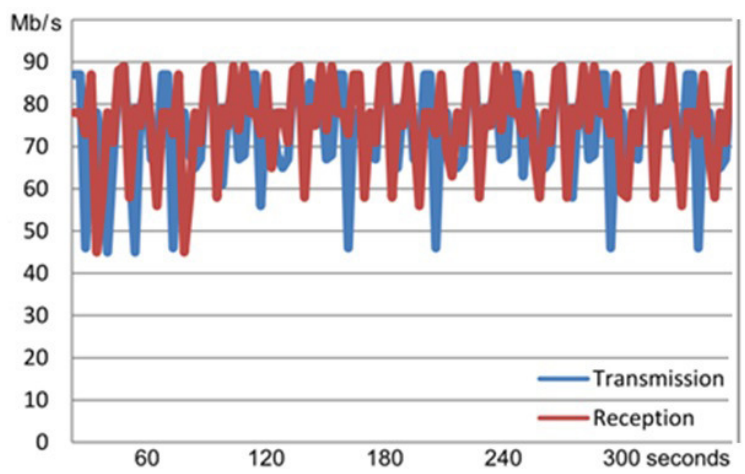

Fig. 11. TX and RX variation, frequency band $13-33 \mathrm{MHz}$.

In the next section, we will verify that the fluctuation of the physical bit rate does not prevent the implementation of a robust TCP / IP link enabling CCTV.

\section{Pilot Site measurements And PRojection of PLC DEPLOYMENT}

\section{A. Link and higher layers}

The used PLC modems are statically routed. They enable the setup of different networks such as TCP/ IP, DHCP, FTP, VLAN, HTTP and operates under different protocols. Tests presented below were carried out with TCP/IP, but in practice, the tramway operating company uses UDP for CCTV, even if UDP is a lossy data transmission protocol, it has high transfer rates.

Our tested V2I PLC network is built in the following way: in each $3 \mathrm{~km}$ section, we set up a static PLC network on the overhead contact line managed by a PLC master modem. In each tram we have an embedded PLC system consisting of a PLC modem configured as repeater and a coupler. Information go from the tramway to the commanding supervision station through the overhead contact line thanks to PLC link.

Results obtained during the $3^{\text {rd }}$ campaign proved the feasibility of PLC link for on-board tramway cameras streaming. But the link was not stable, physical TX and RX changed continuously with the movement of the tram, and the video lagged.

To overcome this, we have developed a more complex system to allow handover, to replace the actual single embedded PLC modem (PLC3 in figure 1). It is based on 2 modems (PLC-3a and PLC-3b) configured as repeaters, a coupler, a layer-3 manageable switch and a platform allowing the analysis of the available links with overhead contact line PLC modems. While PLC-3a transmits video stream to an overhead contact line PLC modem, the second modem PLC-3b detects PLC modems around the tramway and compares bitrates of different available links. If a better link with at least $+5 \mathrm{Mb} / \mathrm{S}$ is available, a novel link is established between PLC-3b and the overhead contact line. The platform switches over between PLC-3a modem and PLC-3b by routing the video stream from one switch port to another without breaking the video stream.
PLC-3a is no longer in charge of video streaming, it then analyses links between tramway and overhead contact lines until it detects a better link, proposing a higher bitrate, then the platform routes videostream from PLC-3b to PLC-3a and so on.

Finally, we set up a stable TCP/IP PLC link with a channel capacity of $80 \mathrm{Mb} / \mathrm{S}$. This result is 10 times higher or even more than those obtained on comparable PLC link on LVDC in [24]. To illustrate the robustness of the PLC link, we carried out several tests simultaneously:

1) The establishment of two real-time video streams with 2 tramway on-board cameras with 1920x1080 pixels resolution (one in the cockpit and the other in the passenger zone, illustrated in yellow in figure 1). One camera with MJPEG video compression [35] and the other with $\mathrm{H} 264$ compression [36]. Both transmitting 30 frames per second. The first camera needs a bit rate of $12 \mathrm{Mb} / \mathrm{S}$ and for the second $4 \mathrm{Mb} / \mathrm{S}$.

2) The second test was sending from the moving tramway a file of $707 \mathrm{Mb}$ to the remote fixed station, parallel to the video stream of the 2 cameras with a bit rate of $1333.20 \mathrm{ko} / \mathrm{S}$ i.e. $10.66 \mathrm{Mb} / \mathrm{S}$.

The average Round Trip Time (RTT) measured from the remote station, based near the tramway line and connected to a PLC static modem, and other PLC modems was about $16 \mathrm{~ms}$. The IP 192.168.9.110 in figure 12 corresponds to the connected on-board PLC modem. The RTT varies between $10 \mathrm{~ms}$ and $62 \mathrm{~ms}$, which corresponds to the minimum and maximum distances between the moving tramway and our static security command post connected to the PLC modem (IP 192.168.9.101). This figure shows some modems of the static PLC installation from IP 192.168.9.101 to 192.168.9.106.

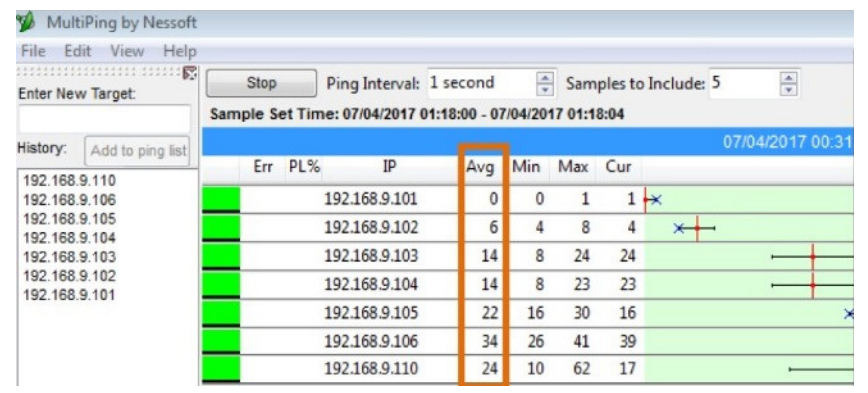

Fig. 12. RTT measured from the remote station.

These latencies, under $62 \mathrm{~ms}$ are comparable to the values obtained on LVDC in [24]. They are also comparable to commercial networks on fiber, ADSL or LTE. For example, the possible order of magnitude for the optical fiber is $19 \mathrm{~ms}$, while the ADSL RTT is around $70 \mathrm{~ms}$ and the LTE around $122 \mathrm{~ms}$ in V2X context [29].

These values were measured when the tram was traveling at an established speed of $50 \mathrm{~km} / \mathrm{h}$.

\section{B. Projection of deployment of PLC solution for moving tramway}

We realized our PoC on $3 \mathrm{~km}$ of the $15 \mathrm{~km}$ of the T2 line which is well representative of the tramway environment 
in this city since it passes under a railway station, on a river bridge, goes along and spans the railway and is crossed by several tramway lines. A PLC device has been placed every $300 \mathrm{~m}$ on average, which remain consistent with the results obtained on LVDC distribution systems [24]. It is also equivalent or even more reliable than V2I solutions based on LTE or IEEE $802.11 \mathrm{p}$, whose probability of packets being delivered is less than $70 \%$ for distances greater than $300 \mathrm{~m}$ [2].

The results obtained over the $3 \mathrm{~km}$ of operation line enable us to quantify the deployment of an entire line by creating PLC sub-networks every $3 \mathrm{~km}$, which are electrically independent but are interconnected from an IP point of view to have a single data network over the $15 \mathrm{~km}$. Indeed, the tramway network of several kilometers can be considered as a redundancy of $3 \mathrm{~km}$ portions. A deployment's topology is illustrated in 13 below:

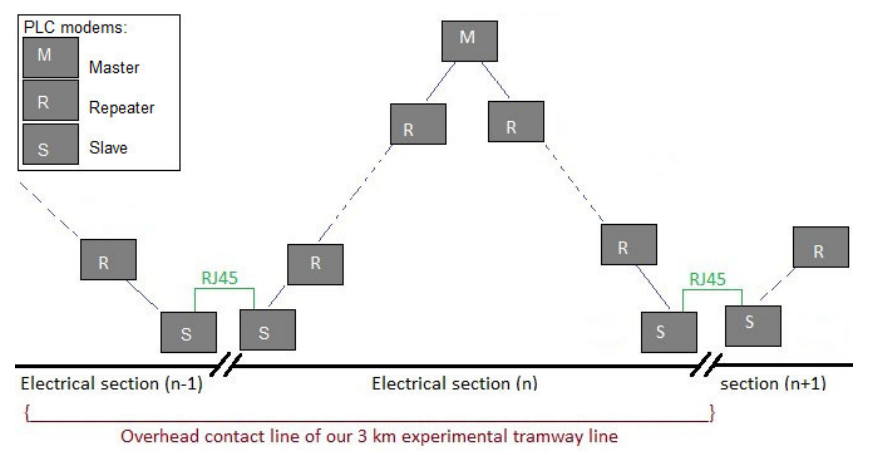

Fig. 13. V2I PLC network deployment topology.

Note that there are about 10 cameras per tram, all the video streams go through the on-board recorder to the security monitoring post. The supervision and surveillance team looks at all the video streams from tramway cameras on an image mosaic and zoom on a specific camera in case of need. This synthetic image (mosaic) has the same resolution as the onboard cameras. The observed values allow us to project in a deployment with an average transmission rate of $60 \mathrm{Mb} / \mathrm{s}$ which allows the video streaming of the embedded cameras of 15 trams simultaneously with IP cameras proposing a compression equivalent or better than $\mathrm{H} 264$ or about 5 tramways simultaneously with compression equivalent to MJPEG. As mentioned at the beginning of the paper, it is possible to assimilate a tramway line to a succession of portions of about $3 \mathrm{~km}$. Therefore, this calculation is available per $3 \mathrm{~km}$ portion, which represents approximately 5 or 6 trams per $3 \mathrm{~km}$ portion. As the Lyon's tramway lines infrastructure does not allow to have more than 6 trams in a $3 \mathrm{~km}$ portion, even in rush hour, the low range of the possible number of video streams meets the need.

\section{CONClusion}

Public transports make great efforts for reducing incidents, improving safety, and mitigating the impacts of traffic congestion. In the context of smart transportation, this article demonstrates the feasibility of implementing a cost-competitive V2I solution for the tramway on-board cameras transmission, based on a broadband PLC link through the existing electrical wiring. We demonstrated this through several real-world tests during which two HD video streams were transmitted from a moving tramway to the security command post. In a top-down approach, we characterized the physical channel (Signal to Noise Ratio, channel capacity, EMC), as well as the PLC link established on this channel (bit rates, round trip times), and demonstrated that it had an equivalent quality to the high-speed wireless solutions such as 5G. This work could be completed by a bottom-up approach, as in [40] where a tram power line is modeled by finite element method up to $10 \mathrm{KHz}$, to perform at least the input impedance of the channel. Unlike wireless solutions as WAVE or LTE, the PLC is not only more cost-effective, but is also more robust in environments, unfavorable to wireless transmissions, such as tunnels. Besides the lower initial capital expense (CAPEX), thanks to its lower implementation cost and installation time, PLC solution has no subscription fees or billing based on the volume of transferred data. Moreover, the PLC link could be used as a backbone for European Rail Traffic Management System (ERTMS). This solution presented through these experiments can also be implemented for trolleybus wiring.

\section{ACKNOWLEDGMENT}

This work is partially supported by the french National Association of Research and Technology (ANRT, CIFRE $\left.N^{\circ} 2014 / 0964\right)$, and Beamtek SAS through a research contract with laboratories (Hubert Curien \& ImViA). Authors are grateful to their colleagues Virginie Fresse and El Bay Bourennane for their advises and BEAMTEK team who spent nights on site preparing these experiments.

\section{REFERENCES}

[1] V. Iordache, R. A. Gheorghiu and M. Minea, "On the usability of Bluetooth in V2I based communications for extended infrastructure support", 13th International Conference on Advanced Technologies, Systems and Services in Telecommunications (TELSIKS), Nis, pp. 287290, 2017.

[2] A. Bazzi, B. M. Masini, A. Zanella and I. Thibault, "Beaconing from connected vehicles: IEEE 802.11p vs. LTE-V2V", IEEE 27th Annual International Symposium on Personal, Indoor, and Mobile Radio Communications (PIMRC), Valencia, pp. 1-6, 2016.

[3] S. Chen, J. Hu, Y. Shi and L. Zhao, "LTE-V: A TD-LTE-Based V2X Solution for Future Vehicular Network", IEEE Internet of Things Journal, vol. 3, no. 6, pp. 997-1005, Dec. 2016.

[4] A. Vinel, "3GPP LTE versus IEEE 802.11p/WAVE: Which technology is able to support cooperative vehicular safety applications?", IEEE Wireless Commun. Lett., vol. 1, no. 2, pp. 125-128, Apr. 2012.

[5] A. Mannan, D.K.Saxena, M. Banday, "A Study on Power Line Communication", International Journal of Scientific and Research Publications, Volume 4, Issue 7, July 2014.

[6] C. Cano, A. Pittolo, D. Malone, L. Lampe, A. M. Tonello and A. Dabak, "State of the art in Power Line Communications: from the Applications to the Medium", CoRR, 2016. Available: http://arxiv.org/abs/1602.09019.

[7] P. Karols, K. Dostert, G. Griepentrog and S. Huettinger, "Mass transit power traction networks as communication channels", in IEEE Journal on Selected Areas in Communications, vol. 24, no. 7, pp. 1339-1350, July 2006.

[8] L. Lampe, A. M. Tonello, T. G. Swart, "Power Line Communications: Principles, Standards and Applications from Multimedia to Smart Grid", Ed. John Wiley \& Sons, 2016. 
[9] W. Gheth, K. M. Rabie, B. Adebisi, M. Ijaz, G. Harris and A. Alfitouri, "Hybrid Power Line, Wireless Communication Systems For Indoor Applications", International Symposium on Communication Systems, Networks and Digital Signal Processing (CSNDSP), Budapest, Hungary, 2018.

[10] Pinomaa, A., Ahola, J., \& Kosonen, A. (2012). "Channel model for a power line communication medium in an LVDC distribution system", IEEE International Symposium on Power Line Communications and Its Applications, 2012.

[11] S. Barmada, A. Gaggelli, A. Musolino, R. Rizzo, M. Raugi, M. Tucci, "Design of a PLC system onboard trains: Selection and analysis of the PLC channel", IEEE ISPLC (International Symposium on Power Line Communications and Its Applications), Jeju City, South Korea, 2008.

[12] T. Larhzaoui, F. Nouvel, J.Y. Baudais, "Feasibility Study of a PLC System for Avionic Safety-Critical Systems", International Journal on Advances in Telecommunications, vol 8 no 1 \& 2, 2015.

[13] C. Jones, "Communications over aircraft power lines", IEEE International Symposium on Power Line Communications and Its Applications (ISPLC), Orlando, FL, USA, Mar. 2006, pp. 149-154.

[14] Zhang, Y.-H., Lin, S.-X., Chen, L.-B., Chang, W.-J., Hu, W.-W., Tang, J.-J., and Yu, C.-T, "An implementation of an in-vehicle power line communication system", IEEE 6th Global Conference on Consumer Electronics (GCCE), 2017.

[15] P. Tanguy, F. Nouvel, P. Maziero, "Power Line Communication standards for in-vehicle networks", International Conference On Intelligent Transport System Telecommunications (ITST), Lille, France. pp.533, 2009.

[16] S. Tsuzuki, M. Yoshida, Y. Yamada, H. Kawasaki, K. Murai, K. Matsuyama, and M. Suzuki, "Characteristics of power-line channels in cargo ships", IEEE International Symposium on Power Line Communications and Its Applications (ISPLC), March 2007, pp. 324-329.

[17] M. Antoniali, A. M. Tonello, M. Lenardon, and A. Qualizza, "Measurements and analysis of PLC channels in a cruise ship", IEEE International Symposium on Power Line Communications and Its Applications (ISPLC), Udine, Italy, Apr. 2011, pp. 102-107.

[18] S. Galli, A. Scaglione, Z. Wang, "For the Grid and Through the Grid: The Role of Power Line Communications in the Smart Grid", Proceedings of the IEEE - Special Issue on Smart Grid, vol. 99, no. 6, June 2011.

[19] W. Saad, Z. Han, H. V. Poor, T. Başar, "Game Theoretic Methods for the Smart Grid", IEEE Signal Processing Magazine, vol. 29, no. 5, pp. 86-105, September 2012

[20] Pinomaa, A., Ahola, J., Kosonen, A., and Nuutinen, P., "Noise analysis of a power-line communication channel in an LVDC smart grid concept", IEEE 17th International Symposium on Power Line Communications and Its Applications, 2013.

[21] Ercan, S. U., Ozgonenel, O., \& Thomas, D. W. P., "Power line communication channel for smart grid", 6th International Istanbul Smart Grids and Cities Congress and Fair (ICSG), 2018.

[22] A. M. Tonello and F. Versolatto, "Bottom-Up Statistical PLC Channel Modeling-Part I: Random Topology Model and Efficient Transfer Function Computation," IEEE Transactions on Power Delivery, vol. 26, no. 2, pp. 891-898, April 2011.

[23] A. M. Tonello and F. Versolatto, "Bottom-Up Statistical PLC Channel Modeling - Part II: Inferring the Statistics," IEEE Transactions on Power Delivery, vol. 25, no. 4, pp. 2356-2363, Oct. 2010.

[24] Pinomaa, A., Ahola, J., \& Kosonen, A., "PLC Concept for LVDC Distribution Systems", IEEE Communications Magazine, 49(12), 55-63, 2011.

[25] Zhang, L., Ma, H., Shi, D., Wang, P., Cai, G., \& Liu, X, "Reliability Oriented Modeling and Analysis of Vehicular Power Line Communication for Vehicle to Grid (V2G) Information Exchange System", IEEE Access, 5, 12449-12457, 2017.

[26] [Online]. Available: https://toulouse.latribune.fr/innovation/2017-1109/toulouse-est-la-premiere-ville-de-france-a-equiper-tout-son-metroen-4g-757416.html (Accessed april 02, 2019).

[27] [Online]. Available: https://www.marketsandmarkets.com/PressReleases/ smart-transportation.asp (Accessed april 02, 2019).

[28] [online]. Available: http://www.beamtek.fr/fr/documentations

[29] H. G. V. d. Andrade and C. C. L. L. Ferreira and A. G. d. S. Filho, "Latency Analysis in Real LTE Networks for Vehicular Applications", VI Brazilian Symposium on Computing Systems Engineering (SBESC), pp. 156-161, 2016.

[30] F. Passerini, A. M. Tonello, "Analysis of High Frequency Impedance Measurement Techniques for Power Line Network Sensing", IEEE Sensors Journal, Special Issue on "Smart Sensors for Smart Grids and Smart Cities". Available: https://arxiv.org/abs/1709.06025v1.
[31] K. Khalil, P. Corlay, F.X Coudoux, M.G. Gazalet and M. Gharbi, "Analysis of the Impact of Impulsive Noise Parameters on BER Performance of OFDM Power Line Communications". Available: https://dblp.org/rec/bib/journals/corr/KhalilCCGG15

[32] B. Adebisi, K.M. Rabie, A. Ikpehai, C. Soltanpur, and A. Wells, "Vector OFDM Transmission over Non-Gaussian Power Line Communication Channels", IEEE Systems Journal, Volume: 12, Issue: 3, 2018.

[33] M. Peck, G. Alvarez, B. Coleman, H. Moradi, M. Forest, V. Aalo, "Modeling and Analysis of Power Line Communications for Application in Smart Grid", IEEE Power and Energy Society General Meeting, San Diego, CA, USA. 2012. Available: https://arxiv.org/ftp/arxiv/papers/1709/1709.06883.pdf.

[34] R. Vial, "Vers un dimensionnement optimal structure commande de systeme multi-convertisseurs : Application aux reseaux de tramways", Ph.D. thesis, University Grenoble Alpes, 2012.

[35] R. Mantiuk, A. Efremov, K. Myszkowski, and H.-P. Seidel, "Backward compatible high dynamic range mpeg video compression", ACM Trans Graphics (Proc. SIGGRAPH), vol. 25, no. 3, pp. 713-723, 2006. Available: https://arxiv.org/ftp/arxiv/papers/1803/1803.04823.pdf.

[36] A. Banitalebi-Dehkordi and M. Azimi and M. T. Pourazad and P. Nasiopoulos, "Compression of high dynamic range video using the HEVC and H.264/AVC standards", 10th International Conference on Heterogeneous Networking for Quality, Reliability, Security and Robustness, Rhodes, Greece, 2014.

[37] Songnong, L., Dong, L., Hongliang, S., Xingzhe, H., Ke, Z., Xin, M., \& Zhishu, L., "Modeling of High-Frequency Low Voltage Power Line Carrier Communication Channel", International Conference on Computer Network, Electronic and Automation (ICCNEA), 2017.

[38] Zhao, X., Zhang, H., Li, L., Lu, W., Ding, Y., and Liu, J. "Modelling and comparison for low-voltage broadband power line noise using LS-SVM and wavelet neural networks", IET Communications, 2018.

[39] N. Andreadou and F. Pavlidou, "Modeling the noise on the OFDM power-line communications system," IEEE Trans. Power Del., vol. 25, no. 1, pp. 150-157, January 2010.

[40] E. Morin, D. Cornic, G. Meunier, N. Retiere, J. Roudet, "Use of a finite elements method to characterize a Multiconductor transmission line problem on a tram groundpowered system", IEEE Compumag, Sarratoga, July 2003

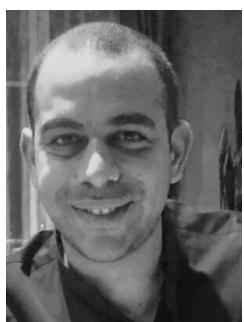

Hatem BELHASSEN (h.belhassen@beamtek.fr) From 2014, he is an engineering project manager at BEAMTEK, a Research and Development company specialized in electricity, designing and commissioning PLC systems. He is actually a Phd student since January 2016, his professor is Mr. EL Bay Bourennane from the ImViA laboratory, University of Burgundy, Franche-Comte, and his co-director is Ms. Virginie Fresse, from the Hubert Curien Laboratory, UJM Saint-Etienne, France.

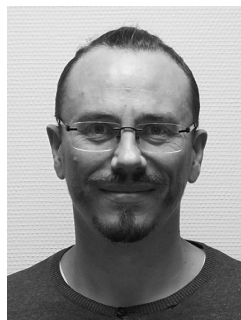

Eric VERNEY (eric.verney@univ-st-etienne.fr) is an associate professor at the engineering school Telecom Saint-Etienne and Laboratory Hubert Curien, University Jean Monnet of Saint-Etienne, France. In 2001, he received his Ph.D. degree in physics from Pierre and Marie Curie University in Paris, he is specialized in microwaves. He works since several years in the field of application of the metamaterials to passive devices for telecommunications. 